\title{
STRUCTURAL ADAPTABILITY OF RESIDENTIAL BUILDINGS: SUSTAINABLE CONCEPTS IN HUNGARIAN HOUSING
}

\author{
BALÁZS KOKAS ${ }^{1}$, JENO BALOGH $^{2}$, ÁGNES BORSOS ${ }^{1}$, \\ GABRIELLA MEDVEGY ${ }^{1} \&$ BÁLINT BACHMANN ${ }^{1}$ \\ ${ }^{1}$ University of Pécs, Hungary \\ ${ }^{2}$ Metropolitan State University of Denver, USA
}

\begin{abstract}
In the last decade, the percentage of the Hungarian population that live in cities has risen to $69.5 \%$ - a percentage which is increasing. This trend will cause housing problems that should be solved in an eco-friendly and economically efficient way. In Hungary, there are options to transform the existing building stock built in the last century, but these solutions have their limits. Alternatives have to be found for designing new residential buildings. The aim of this research is to create a design concept that addresses all aspects of sustainability. The paper presents the structural system derived from a complex sustainability analysis that is at the core of the developed concept. The structural system and the functionality of a building in its current state have certain lifespans. Finding the balance between these lifespans is key to achieving higher sustainability. The social trends and the technological development can modify the needs for a certain building functionality, and, therefore the building will have to be adapted. The possibilities of buildings adaptation were examined through typical Hungarian house types. The study revealed the limitations caused by fixed structural systems and emphasized the importance of structural flexibility. Through examining the existing building stock, a proposal was developed for future housing solutions in Hungary. To ensure the affordability of the system, a prefabricated and a modular system was selected. The resulting concept of an apartment building with high adaptability for an urban setting are discussed. Both new and traditional structural systems were taken into consideration in finding a balance between the functional and structural lifespan. With these building concepts, a possible solution is provided to the upcoming demographic changes, while keeping our ecological footprint small.
\end{abstract}

Keywords: housing, functional lifespan, structural adaptability, sustainable building.

\section{INTRODUCTION}

According to urbanization trends, we construct, demolish, and develop. The depletion of natural resources and the intensification of global environmental and economic issues makes the sustainability aspects much harder to ignore in architecture. Therefore, sustainable buildings require the development of complex concepts that account for the combined economic, environmental, and social needs and effects. The theoretical design concepts can be transposed into practice through the selection of the adequate space delimiters. Thus, the concept can be materialized by the architectural structure.

\section{CONCEPT DESCRIPTION}

In this research, in order to develop the sustainability-driven concepts, general sustainability models and Venn diagrams were analysed in which the three subsystems - economy, environment, and society - appear as overlapping sets [1], [2]. The intersection of these sets represents the sustainable domain. The expectations towards buildings and artificial spaces, and the effects of the construction processes, were analysed according to this model set breakdown and consequently, the impacting factors were determined.

The three phases of the buildings' lifecycle - construction, service, and demolition - were analysed from economic and environmental point of views. The construction and demolition 
phases are fundamentally determined by the adoption of the structural system and the construction technology which determine various materials, labour, and waste management costs. From an environmental point of view, the use of materials can be determined similarly, based on the various energy needs, waste, and pollutant emissions. During the service phase, providing for the user's comfort level and maintenance drive the main costs and environmental impact factors.

The costs per time unit associated with the service phase are generally low, thus a longer service lifetime will typically lead to a more economical solution. This can occur when the building is able to fulfil the user needs emanated from the societal set, such as the functionality, comfort, and aesthetics [3]. Based on the above, from a sustainability point of view, the building service lifetime is of basic importance. Thus, in the design process, based on the complex concept, the functional and aesthetical requirements are determined and paired with a structural solution [4]. Both elements have their own lifespan. For all buildings, the identification of the relationships between the functional and structural lifespans is an important task.

The requirements and needs with respect to various building functionalities are changing differently over the time. Certain functionalities, due to their traditional nature, stay unchanged for centuries (sacred spaces) while other are following the technological advances and societal changes (workplace spaces, certain living functions). Changing needs, to some degree, will occur for all types of buildings, however, depending on the functionality, it could be at a different rate.

As a result of the technical advances, one of the most dynamically varying requirement systems is in the residential construction. Consider a residential house or apartment building built 150 years ago and one designed today. Each of them met the needs of the corresponding era, however, within a few decades, in order to accommodate the changing trends, modifications became necessary. As a result, generally, the question asked is: design a new building or modify the existing?

The quickly formulated answer is "modify the existing", which is not surprising, since this is the more favourable solution from both economic and ecological points of view, and it uses the existing building structure in the already built-in lot. Although this is true anyway in the short-term, if considering the lifetime of the building and taking into account the structural implications as well, it could be found that the structural system could greatly impact the total cost of the modifications as well as the environment [5]. Therefore, it is necessary to analyse the possibility of modifying the existing building, as well as the long-term option of newly constructed buildings.

\section{EXISTING RESIDENTIAL BUILDINGS}

Current efforts aiming to renovate existing buildings in Hungary are focused on the standard houses that were built shortly after WWII such as mass-produced buildings that are uniform and were built based on similar principles and structural solutions. Therefore, a universally applicable renovation plan has to be prepared to modify them that suits characteristics of the buildings.

Prefabricated, so-called "panel" buildings, were built using industrial technology, making up about $20 \%$ of the apartments in an urban setting in Hungary today. Therefore, their transformation and modernization could be a viable housing solution for the coming decades. The standardized building of the rural areas must also be mentioned, which are the so-called "cubes", that have a roughly square floor plan and a hipped roof, and were built from the early 1960's until as late as the 1980s, see Fig. 1. Both of these building types, in their time, were considered modern and easy to build, although with different methods (factory 
manufacturing or local cooperation) with locally available expertise [6]. In the initial period, both panel houses and cube houses received positive feedback, as they quickly and easily solved housing problems. In addition to that, panel houses could provide a level of comfort to the people living in them that was not available earlier [8].

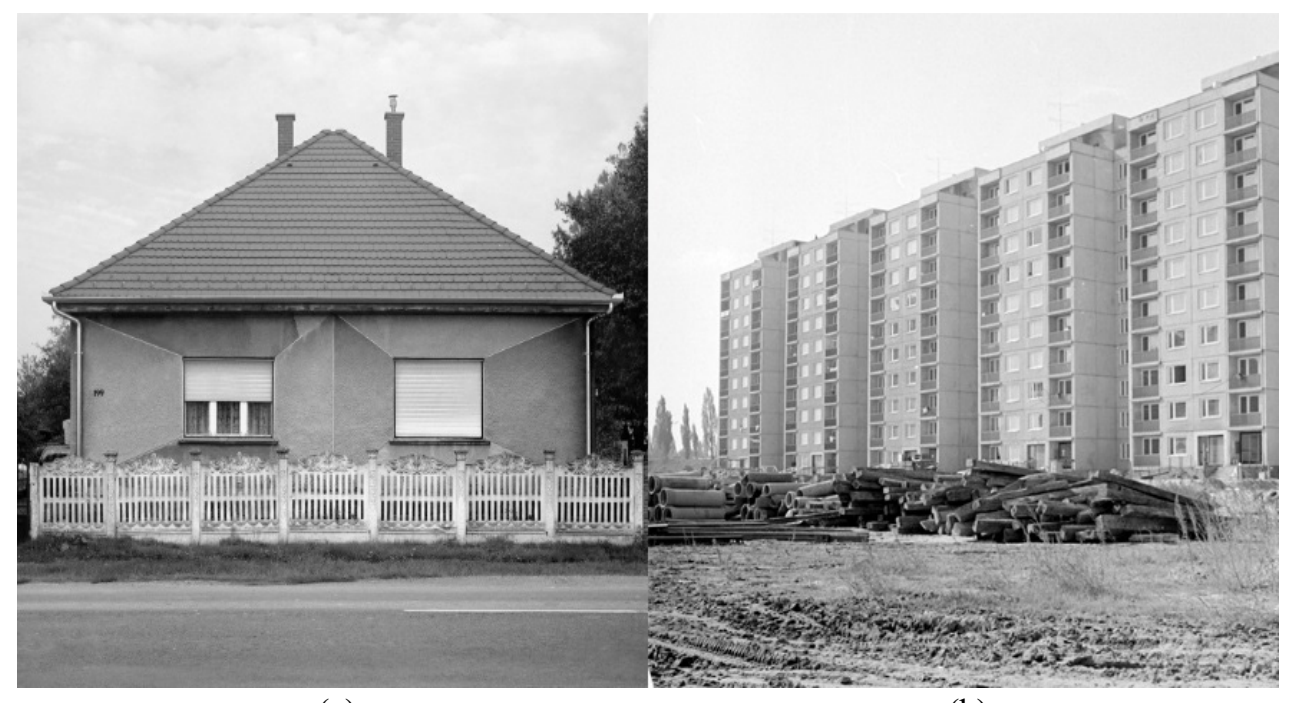

(a)

(b)

Figure 1: (a) Hungarian "cube" rural building; and (b) "panel" urban buildings. (Source: Roters [6] and VÁTI [7].)

\section{1 "Panel" urban buildings}

Although their structural lifespan expectation exceeds 100 years, the "panel" buildings became functionally obsolete within 30 years. Thus, they have to be modified in order to fulfil the new functional demands.

In Hungary, the adopted basic module size for the "panel" apartment buildings are $90 \mathrm{~cm}$. Accordingly, the transverse structural dimensions were $2.7 \mathrm{~m}$ or $3.6 \mathrm{~m}$, while the length, was typically $5.4 \mathrm{~m}$. The small transverse size significantly limited the quality of the achievable spaces. The narrow-span solid-wall system provides only for a limited number of variations, and therefore can only partially adapt to various needs. There are two methods to modify "panel" apartments: by technical upgrade and interior design leading to a higher comfort level, or by layout configuration modifications leading to topological changes. The second, due to structural engineering reasons, is not always possible, although it would be the only way to provide for addressing the new functionality needs [9].

For topological changes, the modification of reinforced concrete structural elements is required, which require structural engineering and architectural solutions. In certain cases, by fully or partially relocating partition walls, the spaces and their ratios could be changed to some extent. The limitations are mainly due to intermediate structural members, water and sewer utilities, and various cut-outs, see Fig. 2. The fixed structural elements within the inner space significantly reduce the modifiability of the building. 


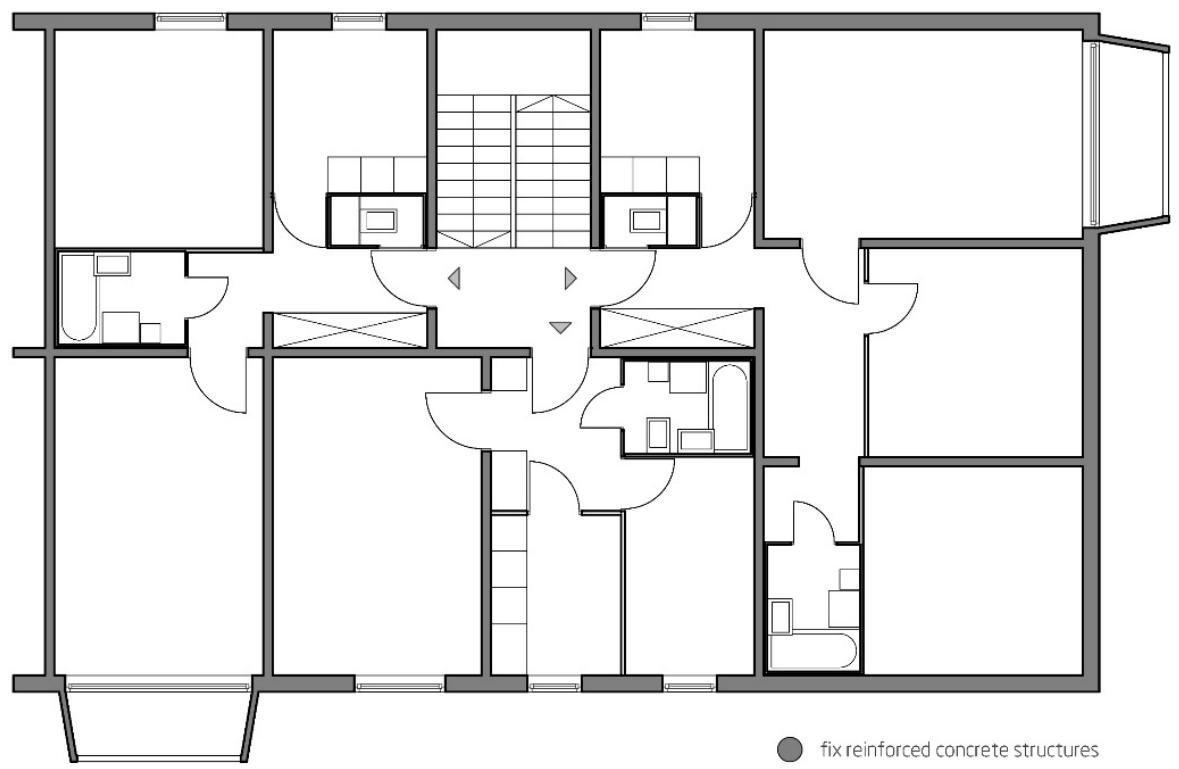

Figure 2: Layout of a "panel" urban building.

\section{2 "Cube" rural buildings}

In the case of the rural standardized "cube" houses, the structural modifications were more feasible and the existing floor sizes are better suited to accommodate the changing needs. Usually, the comfort level is improved with minimal structural modification, by separating the private and public spaces. This allows for closer connection to outside spaces such as gardens or yards. The materials used to create the new partitions are typical to light-frame construction and advantageous due to their construction speed, light loads, and future adaptability leading to less waste, see Fig. 3.

ORICINALLAYOUT

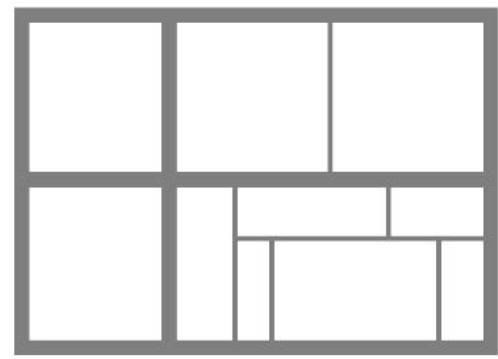

existing solid strucutres

new construction lightweight frame walls

demolished structures
MODIFIED LAYOUT

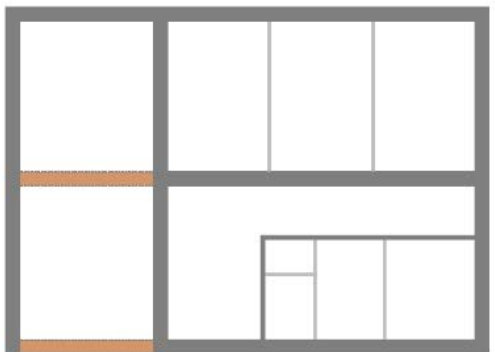

Figure 3: Reorganization of a "cube" rural building. 


\section{NEW CONSTRUCTION RESIDENTIAL BUILDINGS}

There is a genuine demand for new, innovative houses, simultaneously to the rebuilding of the existing buildings. It is often heard that a newly built building should satisfy current demands in every respect. Do "current demands" really exist, and what actually are these? Probably, the most time-resistant solution can be the one in which the rebuilding is simple. Thus, concepts for flexible buildings should be created [10].

In the environment, there are numerous factors that work in the same way for everyone, such as temperature, humidity, audio and light effects, etc. Newly designed residential buildings should fully satisfy these requirements [11]. Based on individual life situations and different personalities, people can have significantly different individual requirements for housing. Therefore, flexible and variable functional layouts should be created, and the structure of the building must incorporate various layouts, which results in multiple façade configurations [12]. Ideally, it should also allow for renovations in the future.

Maximizing the comfort level of the residents is a basic element of the concept. The closeness of the natural environment and the intensive relationship with it is indispensable toward provide healthy living conditions. Besides allowing the visual and physical connection, natural lighting and natural ventilation must also be an integral element of the concept. Based on these considerations and after analysing several contemporary buildings [13] the concept of a seven-story modular apartment building, which fits well in a general urban setting, was developed.

The capital cost of prefabricated buildings is higher than the cost of conventional solutions [14]. However, cost management and changes within the Hungarian construction industry could change this in the future. Shortage of workforce is more and more typical in the construction industry in Hungary. The time required to construct buildings with wet technologies is substantial, thus it is worth examining the possibilities that alternative, dry technologies could offer from this aspect as well. With careful planning and preparation, buildings using such technologies could represent an economical solution.

Other researchers propose models for quantitative measurements of the waste production in prefabricated and conventional scenarios [15]. The aim of this research, however, is to optimize the above factors and processes in order to minimize the ecological footprint of the planned building.

\subsection{Module definition}

The building's system consists of two zones: one for community use, at the lower levels, and the other, at the higher levels, for residential use. The pillar of the concept is the modularity and the adoption of the basic module elements, since the modifiability and customization flexibility are functions of these (see Fig. 4).

According to the main function of the building, the module units are determined by the residential zone [16]. In a building designed with a modular concept, the basic module size is critical from the functionality and structural point of views. The most significant problem with the modular prefabricated products is the monotony and uniformity. In this case, this can be eliminated with an adequate module size $(30 \mathrm{~cm} \times 30 \mathrm{~cm})$ that allows for a high number of variations.

\subsection{Material selection}

The selection of the construction materials followed the principles described above and it is illustrated in Fig. 5. 

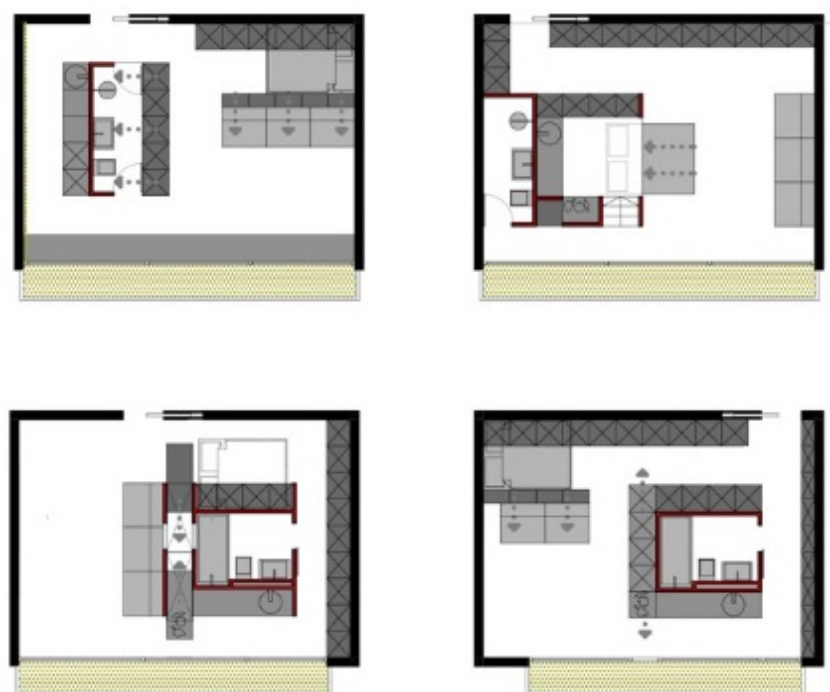

variable partition walls

Figure 4: Flexibility of the living area - layout versions.

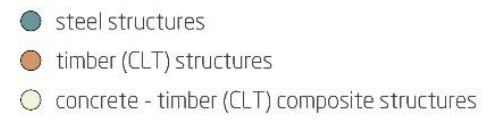

concrete - timber (CLT) composite structures

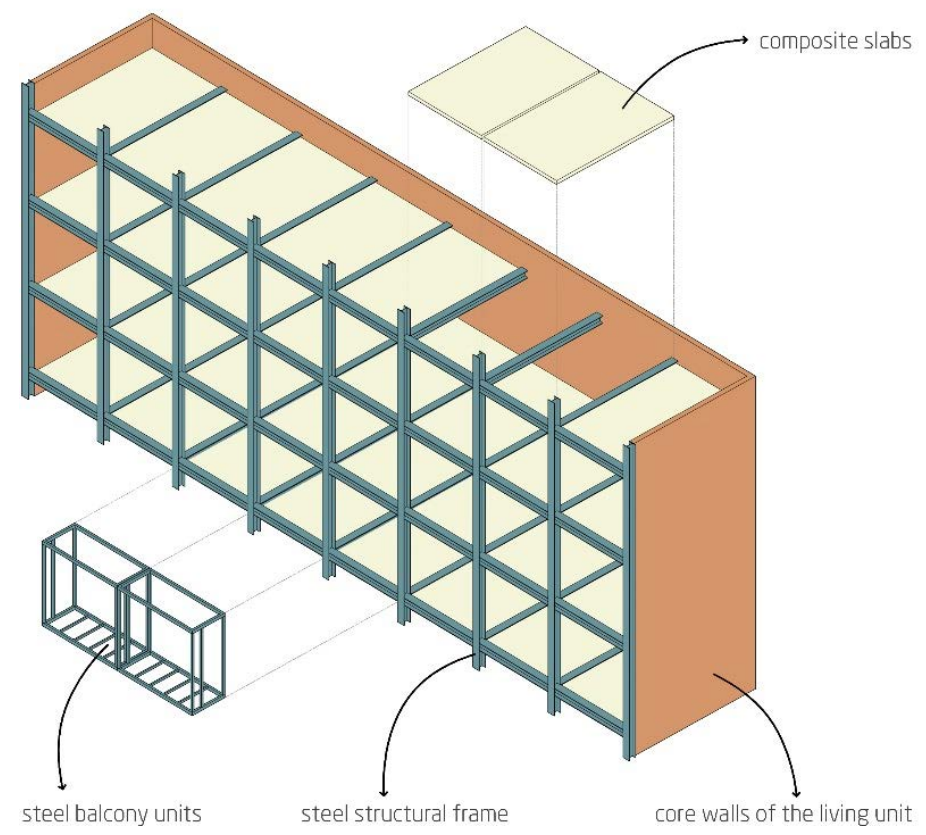

Figure 5: The composite structural system. 


\subsubsection{Timber}

The impact of the timber, a natural construction material, on the comfort perception is different than that of an artificial material. It is generally considered to have a positive impact as it creates a warm and cosy atmosphere. Ecologically and energetically the timber construction material is also considered advantageous. Based on economic and environmental considerations, cross-laminated timber (CLT) was proposed for the structural walls of the building [17], which delimit the living spaces on three sides.

\subsubsection{Concrete}

The use of the reinforced concrete was minimized due to its environmental impact. Other than in the parking and community zone at the lower levels, concrete was only used as part of the timber-concrete composite floor system [18]. Such a floor system uses the timber and the concrete materials in the most efficient way.

\subsubsection{Steel}

Energetic and ecologic considerations started driving architectural solutions more strongly in the second half of the 20th century. Steel became regarded, for multiple reasons, more and more disadvantageous, however its recycling potential cannot be disregarded. In addition, its ability to span large spaces with reasonable member sizes and to connect or disconnect members also makes it the most suitable for a modular application. For the façade, the use of steel enables a flexible configuration/reconfiguration of the balconies over the lifespan of the building.

\section{CONCLUSION}

Sustainable design concepts were developed for existing and new residential buildings in Hungary. While the functionality of the buildings determines the dimensions of the spaces and the requirements, the selection of the materials and structural system will determine the properties of the building for their entire lifespan. An ideal structural system is in accord with its functionality and takes into account the local conditions through the environmental, psychological, and societal comfort factors. If all of these are met, the cost of construction, demolition, and service could be reduced, as well as the environmental impact. With these passive solutions, the degree of comfort could be increased while leading to high-quality aesthetics. From economic, environmental and societal points of view the material and structural system selection is decisive and is therefore one of the key pillars of the sustainability-driven architectural concept.

\section{ACKNOWLEDGEMENT}

The research was performed within the framework of the partnership between the authors' corresponding universities.

\section{REFERENCES}

[1] Todorov, V.I. \& Marinova, D., Models of sustainability. Presented at 18th World IMACS/MODISM Congress, Cairns, Australia, 2009.

[2] Diesendorf, M., Sustainability and sustainable development. Sustainability: The Corporate Challenge of the 21st Century, eds D. Dunphy, J. Benveniste, A. Griffiths, \& P. Sutton, Allen \& Unwin: Sydney, pp. 19-37, 2000.

[3] Ertsey, A. \& Medgyasszay, P., Fenntartható építészet (Sustainable architecture), TERC: Budapest, 2017. 
[4] Imam, S. \& Sinclair, B.R., Dysfunctional design + construction: a cohesive frame to advance agility in the 21st century. ARCC-EAAE Conference, pp. 415-423, 2018.

[5] Gijsbers, R. \& Lichtenberg, J.J.N., Comparison of adaptability measures in building design - CSAMethod: Functionally effective and technically efficient design founded on (future) user demands. 12th International Conference on Design \& Decision Support Systems in Architecture and Urban Planning, pp. 1-16, 2012.

[6] Hornyik, S., A posztkommunista "magyar kocka" (The post-communist "Hungarian cube”), Magyar Építőmüvészet website, 2014. https://meonline.hu/archivum/aposztkommunista-magyar-kocka/.

[7] Kiss, D., Kádár-kocka, panelház, vagy lakópark - Hol lakik a magyar? Lechner Tudásközpont website, Parasztház, 2017. http://lechnerkozpont.hu/cikk/paraszthazkadar-kocka-panel-vagy-lakopark-hol-lakik-a-magyar/.

[8] Entwerfen im System - Der Architekt Wilfried Stallknecht; DDR-Planungsgeschichte website, 2018. http://ddr-planungsgeschichte.de/wp-content/uploads/2018/06/katalog stallknecht.pdf.

[9] Körössi, É. \& Szalánczi, G., Szent István Egyetem Építészeti Adatbázis website, Épülettervezés segédlet, 1994. http://arc.sze.hu/eptervea/jegyzet_Epulettervezes.pdf.

[10] Zivkovic, M., Kekovic, A. \& Kondic, S., The motives fo application of the flexible elements in the housing interior. Facta Universitatis Series: Architecture and Civil Engineering, 12(1), pp. 41-51, 2014.

[11] Hausladen, G., De Saldanha, M., Liedl, P. \& Sager, C., Climate Design, Birkhauser: Basel, 2005.

[12] Schneider, T. \& Till, J., Flexible Housing, Architectural Press: UK, 2007.

[13] Webb, M., Building Community: New Apartment Architecture, Thames and Hudson: London, 2017.

[14] Xue, H., Zhang, S., Su, Y. \& Wu, Z., Factors affecting the capital cost of prefabrication: A case study of China. Sustainability, 9, p. 1512, 2017.

[15] Li, Z., Shen, G.Q. \& Alshawi, M., Measuring the impact of prefabrication on construction waste reduction: An empirical study in China. Resources, Conservation and Recycling, 91, pp. 27-39, 2014.

[16] Borsos, A., Balogh, J., Kokas, B. \& Bachmann, B., An eco-approach to modularity in urban living. International Journal of Design \& Nature and Ecodynamics, 14(2), pp. 83-90, 2019.

[17] Brandner, R., Flatscher, G., Ringhofer, A., Schickhofer, G. \& Thiel, A., Cross laminated timber (CLT): Overview and development. European Journal of Wood and Wood Products, 74, pp. 331-351, 2016.

[18] Balogh, J., Laminated wood-concrete structural members. Pollack Periodica, An International Journal for Engineering and Information Sciences, 8(3), pp. 79-86, 2013. 